\title{
7 Misapplications and Misconceptions of Erosion Models
}

\author{
G. GOVERS \\ Physical and Regional Geography Research Group, Department of Earth and Environmental Sciences, \\ Katholieke Universiteit Leuven, GEO-Institute, Celestijnenlaan, Heverlee, Belgium
}

\subsection{Introduction}

Soil erosion modelling has a long history. The need for accurate soil loss prediction emerged in the 1930s in the United States, after the Dust Bowl. The first models, predecessors of the USLE (Universal Soil Loss Equation), began to appear in the 1940s (e.g. Zingg, 1940), and models have been evolving ever since, albeit not continuously. Erosion model development saw a major paradigm shift from so-called statistical or empirical models to so-called process-based models in the 1980s, mainly stimulated by seminal papers by Foster and Meyer from 1972 onwards (Foster \& Meyer, 1972). Present-day process-based erosion models such as WEPP (Nearing et al., 1989) and PESERA (Kirkby et al., 2008) often are sophisticated tools, describing erosion processes in great detail. Some of them are now able to carry out continuous simulations instead of event-based simulations; others just provide long-term average estimates. One might therefore expect that, by now, we have a clear view on what we may achieve with soil erosion models and how we should apply them. As the title of this chapter suggests, this may not always be the case.

In this chapter we try to understand how and why misconceptions about soil erosion models might arise, and what kind of misapplications of

Handbook of Erosion Modelling, $1^{\text {st }}$ edition. Edited by R.P.C. Morgan and M.A. Nearing. (C) 2011 Blackwell Publishing Ltd. models continue to exist. We will take a somewhat provocative stance, not because we think that most of the work that has been carried out hitherto was substandard or ill-conceived, but because we want to stimulate the discussion. It should also be made clear that both issues have been discussed before: Wischmeier (1976) has already warned against the misuse of the USLE, and since then several critical papers on soil erosion model applications have been published (Boardman, 2006; Jetten \& Favis-Mortlock, 2006; Jetten et al., 2003). Furthermore, critical considerations on the use of spatial models in related fields such as geomorphology and hydrology also exist (e.g. Grayson et al., 1992). Here, we try to provide the reader with a general overview of model misconceptions and misapplications with respect to soil erosion models: logically, some of the material covered has already been discussed in this earlier work. We also take a rather practical, empirical viewpoint. We thereby mostly forego more philosophical/conceptual issues related to spatial modelling in the Earth Sciences : see Bras et al. (2003) for a more conceptual discussion of the issue.

Evidently, misapplication and misconceptions about erosion models are strongly related. Misapplications of erosion models are, in principle, always due to a misconception. On the other hand, not all misconceptions necessarily lead to misapplications. In this chapter we will first discuss misapplications: we will deal with what might be called true misapplications: model 
applications that will lead to erroneous results because there are fundamental reasons why the model is not applicable to the conditions/environment under study. Thereafter we will give attention to other misconceptions about erosion models that may not necessarily lead to erroneous model applications. Such misconceptions may, for instance, hamper a correct interpretation of application results and/or may have important implications in directing future research on soil erosion modelling.

\subsection{Misapplications of Soil Erosion Models}

The issue of misapplications of erosion models can, in principle, be dealt with at a very conceptual level: models can only work when they are applied to conditions for which they have been calibrated and, if possible, validated. The term 'conditions' has, in this context, a very broad meaning: the model should be applied at the correct temporal and spatial scales, and care should be taken to ensure that the model accounts for the erosion processes under consideration. Only model applications where these conditions are met can be considered to be scientifically valid: if these conditions are not met, model applications may lead to the wrong conclusions about the model's performance, the erosion risk in a certain area and/or the efficiency of erosion control measures (e.g. Nyssen et al., 2006).

\subsubsection{The time-scale}

The classic example of model misapplication due to an inappropriate time scale is the use of the USLE at time-scales for which this statistical model was not intended. In their original paper, Wischmeier and Smith (1965) clearly stated that a measurement period of over 20 years was necessary in order to establish a true mean soil erosion rate that could be compared with the value predicted by the USLE. As discussed by Wischmeier and Smith, one of the basic reasons for this is that statistically based models such as the USLE are not capable of accounting for the considerable temporal variation that occurs in soil erosion rates: the model is conceived to represent an 'average annual' situation based upon average annual values for the temporally varying input parameters (most notably rainfall erosivity, soil erodibility and soil cover). Using such a model to simulate what will happen over a short time period or during a single event will inevitably lead to poor results if the system under consideration is characterized by a high temporal variability.

Soil erosion rates do indeed vary significantly over short time-scales, even if all controlling factors except climate (crop type, tillage techniques, soil type, etc.) are kept as constant as possible. Figure 7.1 shows the variation of mean soil erosion rates as measured on three plots under continuous corn at the USDA-ARS research station of Clarinda, illustrating the enormous variability in annual erosion rates. This variability results in a large uncertainty in average erosion rates at a given location, even when measurements are maintained for a long period of time. Coefficients of variation of the mean value decline somewhat with average soil losses but are generally between 0.2 and 0.5 , indicating that, even when measurements are maintained for as long as $10-27$ years, the $90 \%$ confidence interval on the mean is between 40 and $100 \%$ of the measured average value (Fig. 7.2).

Evidently, this variation is partly due to yearly variations in climatic conditions at the station's location, and this variation might be accounted for by using annual rainfall erosivity values rather than an overall average annual value. However, climatic variability is only one component of overall variability: variability is also due to variations in plot conditions that cannot be accounted for by the factors included in the original USLE, and one therefore cannot expect that this variation can be simulated or predicted using a model that was designed to predict correctly average values only, such as the USLE.

The implications of this simple observation are perhaps more profound than we usually think. First of all it means that a meaningful calibration of a model of the USLE-type using field data requires the collection of erosion rates under standardized conditions over a sufficiently long 
Fig. 7.1 Variations of soil losses under continuous corn as measured by the SCS on three replicate plots between 1932 and 1943. Annual soil losses range from 6 to $355 \mathrm{t} \mathrm{ha}^{-1}$ (data source: National Soil Erosion Research Laboratory USLE data repository, Purdue).

Fig. 7.2 Coefficient of variation of the mean as a function of average annual soil loss rates measured in USDA-ARS research stations under different land uses/crop rotations. Measurement periods ranged between 10 (Morris) and 27 years (Guthrie) (data source: National Soil Erosion Research Laboratory USLE data repository, Purdue).
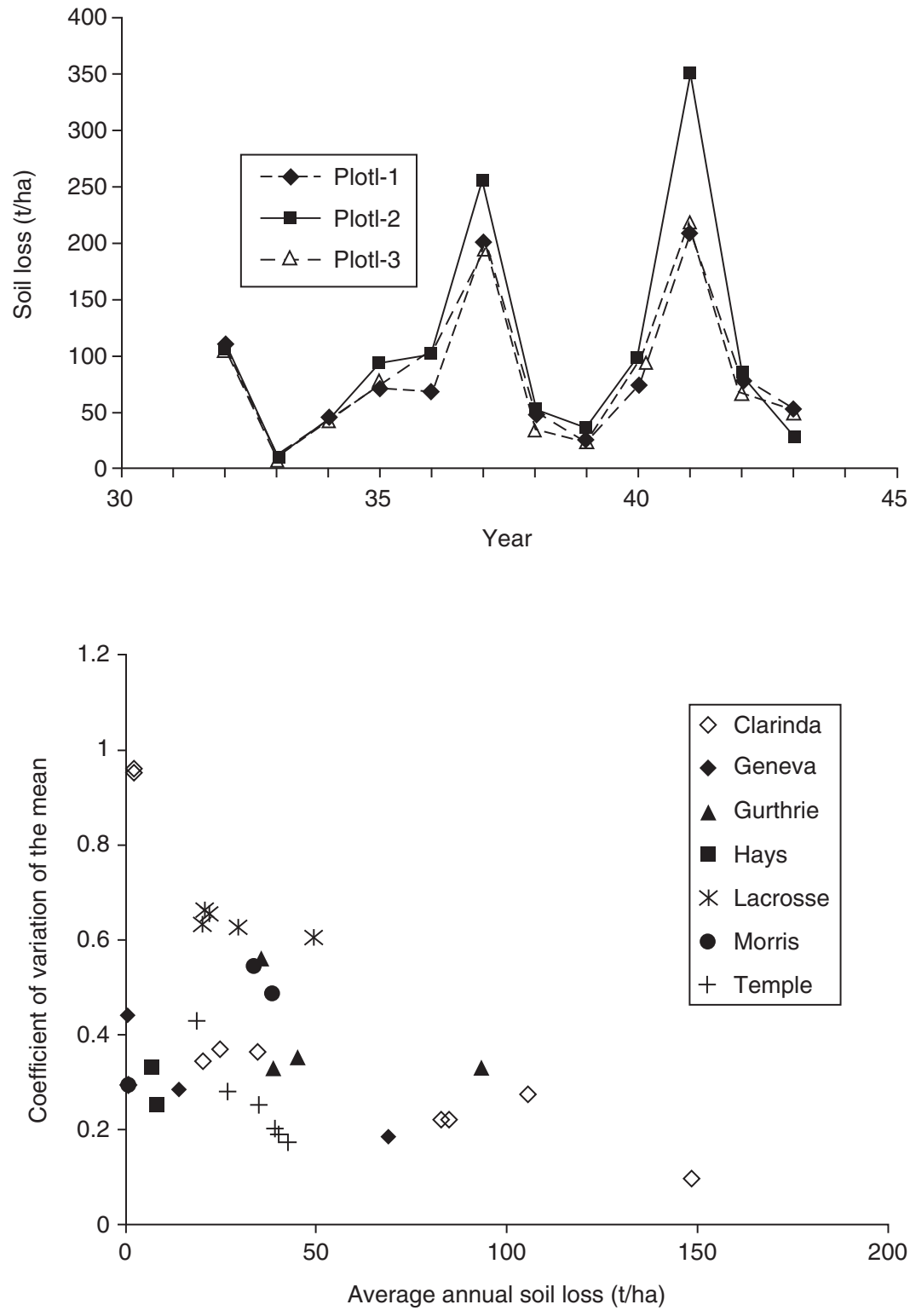

time period: at least 10 years seems reasonable, but Wischmeier and Smith (1978) considered 20-22 years to be desirable, as measurements should cover a full solar cycle. Very often data are not available for such a long time period. Plot replication cannot entirely solve this issue, as measuring for a shorter time period may imply that the climatic and vegetation conditions during the measurement period are not representative of the 'true mean'. Alternatively, integrative techniques, assessing soil redistribution rates over longer time spans through a single measurement, 
may be used, but they need to be applied with care (see below). Logically, the decadal time span requirement does not only apply to model calibration, but also to model evaluation/validation: even then, only the average annual soil erosion value should be compared. These considerations are not only relevant for the USLE: a more recent model such as PESERA (Kirkby et al., 2008) uses a process-based approach to model long-term average water erosion. Yet, it relies on average climatic characteristics (basically the number of rain days per month and the amount of rain per rain dayl to calculate the distribution of runoff events. Hence, long-term data on average annual erosion rates are in principle necessary to evaluate its performance.

One might argue that a large part of the investments made in the development of the Revised Universal Soil Loss Equation (RUSLE), the followup model of the USLE, as well as the development of other, dynamic, process-based models, were precisely directed towards a better accounting of the temporal variability in factors controlling erosion. This is, for instance, clearly apparent in the new procedure for the calculation of the soil erodibility factor that was incorporated in the RUSLE (Renard et al., 1997); in the USLE, soil erodibility was characterized by a single number, while in the RUSLE a detailed procedure is implemented allowing for temporal variability (see Chapter 8). Experimental and field work had indeed demonstrated that soil erodibility could be highly variable (e.g. Mutchler \& Carter, 1983). The developers of the RUSLE used the available experimental data to develop seasonal soil erodibility factors so that the model could in principle account for seasonal changes such as variations in soil moisture, freezing and thawing and soil consolidation. Similarly, the calculation of the cover factor (C) was refined in an attempt to improve the model's capability of accounting for temporal variations in soil cover as well as of the role of the various components of soil cover (canopy and surface). These modifications make it in principle possible to apply the RUSLE to much shorter time spans in comparison with the USLE, as temporal variability is explicitly accounted for.
Process-based models incorporated in a continuous soil-plant simulation model, such as the current WEPP model, are, in principle, applicable to even finer temporal scales, since such models simulate erosion using time-steps of seconds. This temporal resolution is large enough to simulate the variation of erosion within a single event. In the WEPP system, variations in soil conditions (moisture, roughness, density), plant development (growth stage, vegetation cover) and surface cover that may affect erosion rates are updated between each event (Flanagan \& Nearing, 1995).

Given the increased time resolution of these models, one would expect them to be better able to predict erosion rates on a seasonal or yearly basis than the USLE, even when the latter is applied using temporally adjusted input values for soil cover and rainfall erosivity. This is in principle easy to test by (i) comparing average annual values as predicted by the USLE and a more sophisticated model such as the RUSLE or WEPP with measured averages; and (ii) by comparing individual annual or seasonal values as predicted by the USLE and a more recent, sophisticated model with measured annual or seasonal values. Yet, there are very few studies empirically investigating these issues. The author is not aware of any literature that empirically substantiates the proposition that RUSLE is indeed capable of better prediction of seasonal variations in erosion rates than the USLE when the latter is applied using seasonally varying input data. However, some intercomparisons of process-based models, the USLE and/or RUSLE have been carried out. Such studies have consistently shown (i) that dynamic, process-based models are often not capable of simulating individual events adequately (Jetten et al., 1999; Favis-Mortlock et al., 2001); and (ii) that, when predictions of average annual values or individual annual values of soil erosion rates are considered, dynamic, process-based models often perform similarly or only marginally better than statistical models. Using 1600 plotyears of data, Tiwari et al. (2000) compared predictions using the WEPP, USLE and RUSLE models. WEPP recorded a model efficiency of 0.71 compared with 0.80 and 0.72 for USLE and RUSLE 
respectively, when average annual values were compared, showing that, in terms of predicting long-term average values, the USLE outperformed more recent, sophisticated models. When looking at individual annual erosion values, one should expect the difference between the different models to reverse. However, Tiwari et al. (2000) found that this was not the case, as model efficiencies were $0.58,0.60$ and 0.40 for USLE, RUSLE and WEPP respectively. Thus, at higher temporal resolution the USLE performed similarly to the RUSLE and somewhat better than WEPP.

With respect to event-based erosion modelling, nearly all studies that have been carried out hitherto demonstrate that the application of erosion models to single events often results in very large errors (e.g. De Roo \& Jetten, 1999), suggesting that even dynamic, process-based models should not be used or evaluated at the time-scale of a single event. However, they offer a key advantage in comparison with statistical models when it comes to predicting the dynamics of erosion processes, in that they can generate distributions of individual events; it is then not only possible to compare the predicted, average values, but also the simulated distribution of events, so that insight can be gained into what type of event causes most erosion. We may then anticipate how this distribution may shift with a changing climate or a changing agricultural system (Baffaut et al., 1998).

\subsubsection{The processes}

Obviously, a model should only be used to simulate those processes that it describes. Most water erosion models describe so-called 'sheet and rill' erosion, thereby excluding the effects of soil redistribution by other processes. A valid test of such a model can therefore only be carried out using data on sheet and rill erosion rates. The latter appears to be obvious, yet misapplications occur mainly when direct data are not available and sheet and rill erosion rates are equated to total soil redistribution rates which are measured by looking at an integrative measure of soil redistribution. The latter may, for instance, be the degree of soil redistribution or soil erosion/ deposition rates calculated from radionuclide inventories (mostly ${ }^{137} \mathrm{Cs}$ ) or soil truncation.

Integrative measures of soil redistribution provide valuable information about the intensity of soil redistribution rates, but both rates and patterns may be affected by other processes than sheet and rill erosion. On arable land, tillage erosion, ephemeral gully erosion and soil loss by root crop harvesting can all significantly contribute to soil redistribution, and their impact may even dominate the overall soil redistribution pattern. Data from integrative tracers can therefore not be used directly to validate a model that was specifically developed to simulate sheet and rill erosion such as the USLE or WEPP. While in past studies, ${ }^{137} \mathrm{Cs}$-derived erosion rates and water erosion model predictions were sometimes directly compared since researchers were not aware of the importance of tillage erosion or root crop harvesting (e.g. Busacca et al., 1993), recent literature shows that researchers have become increasingly aware of the fact that, given the importance of other soil redistribution processes, all processes contributing to soil redistribution need to be accounted for when interpreting the results of tracer and/or soil truncation studies (e.g. Belyaev et al., 2005).

\subsubsection{The spatial scale}

There are several reasons why spatial scale is important for erosion model applications. Firstly, different processes dominate erosion at different scales. For instance, in Europe tillage erosion is often the dominant erosion process at the field scale (Govers et al., 1994). Yet, at the catchment scale tillage does not cause any net soil movement as all soil that is eroded by tillage is redeposited within the same field. A possible solution to this is to view the landscape as a hierarchically structured set of response units, each with their own dominant processes described by relevant submodels (Cammeraat, 2002). A second reason why scale issues are important is that model parameters are often obtained from measurements at a scale that is different from the one at which the model is finally used: model parameters, such 
as saturated hydraulic conductivity, are often estimated using rainfall simulation experiments at a scale of ca. $1 \mathrm{~m}^{2}$, while models are applied at the field or even the catchment scale.

The above does not imply that erosion models can only be applied at the scale that was used for parameter estimation or erosion rate assessment during model development. What is necessary, though, is that scaling is carried out appropriately and that the results obtained at different scales are interpreted correctly.

Making sure that scaling is appropriate is of tremendous importance when average erosion rates over large surface areas need to be estimated. The advent of GIS software has made the manipulation of large spatial datasets much easier, and over recent years several global estimates of soil erosion have been produced (Yang et al., 2003; Ito, 2007; Van Oost et al., 2007); the accuracy of such estimates depends critically on the use of correct scaling factors. For simple, topographically-driven models the length or area factor that is present within the model can be considered as a scaling factor. If the erosion rate per unit surface area increases with increasing slope length, average erosion rates measured on small plots will be lower than average regional soil erosion rates. If, on the other hand, the erosion rate decreases with increasing slope length/contributing areas, average regional erosion rates will be lower than average soil erosion rates. The slope length effect may vary considerably, depending on local conditions and the type of erosion process. In RUSLE calculations it is assumed that erosion scaling with slope length depends on the ratio of rill to interrill erosion, which is primarily controlled by slope gradient but may also depend on other factors such as soil type and soil conditions (Loch, 1996; Renard et al., 1997). If inter-rill erosion is dominant, the length factor can be small (the length exponent is close to zero), which implies that erosion rates are more or less constant as a function of slope length. If rill erosion is dominant, the length exponent is assumed to be much higher (approaching 1), which implies that erosion rates increase with increasing slope length/ contributing areas.
There is a significant, albeit relatively small, amount of experimental data backing up the slope length factors that are generally used for arable land, especially for cases where rill erosion is dominant (Govers et al., 2007). However, the situation may well be different on hillslopes under natural vegetation: under these conditions, erosion rates per unit surface area may well decrease with increasing slope length, the fundamental reason being that total runoff amounts do not increase, or increase only slowly with increasing slope length, as the spatial variability of hydraulic conductivity is very high and increasing water depths promote increasing infiltration (Dunne et al., 1991). Net erosion rates on such slopes will then become limited by the amount of sediment that can be transported by overland flow off the slope. If time-averaged transport capacity does not increase at least linearly with slope length, erosion rates per unit area will decrease with increasing slope length as proposed by Parsons et al. (2006). Slope length factors used in (R)USLE applications on non-agricultural land should be adjusted accordingly, but experimental data on the variation of sediment fluxes with slope length on surfaces with natural vegetation is at present very scarce.

Process-based models generally model runoff generation and transfer explicitly: they are therefore in principle capable of simulating erosion at larger scales without an a priori specification of a length or area factor. However, this evidently requires that the mechanisms controlling the scaling of runoff generation and transfer are explicitly accounted for in the model. If, for instance, a model is applied in an environment where infiltration rates are increasing with increasing water depth while the model description of infiltration and runoff generation does not allow for this, the model may be expected to perform badly when applied to slopes of greater length than that of typical erosion plots (1-20m).

Another issue that may cause misapplication at large scales is that the erosion response of a larger catchment is not only controlled by the amount of rill and inter-rill erosion, but also by 
other erosion processes such as (ephemeral) gully erosion, landsliding and river incision and/or bank erosion and, importantly, also by sediment deposition. There is therefore no direct relationship between simulated or predicted erosion rates and river sediment yield. Accounting for sediment deposition is extremely important, given that in many cases up to $80 \%$ of the eroded sediment is (re)deposited within a short distance $(<10 \mathrm{~km})$ of the sediment source (Van Rompaey et al., 2001; Wilkinson \& McElroy, 2007). Relationships between catchment sediment yields and soil erosion rates are further complicated by the fact that, at the catchment scale, internal mechanisms lead to compensatory effects: a decreased sediment supply from the slopes due to the implementation of soil conservation measures may lead to increased mobilization by the river of previously deposited sediment through bank erosion and incision, so that sediment yield is maintained over a long time period (Trimble, 1999). The poor relationship between soil erosion rates and river sediment yields is well illustrated by the fact that the massive increase of soil erosion due to agricultural activities has only led to an increase of global river sediment fluxes from the land to the ocean by ca. $20 \%$ (Syvitski et al., 2005). One may therefore expect that using an inverse approach (i.e. estimating soil erosion rates from total river sediment fluxes) may lead to errors; a substantial overestimation of soil erosion rates on agricultural land in large catchments may result if sediment yields are back-converted to erosion rates using a simple sediment delivery approach (Lal, 2003).

The above does not imply that coupling river sediment yields to erosion rates is never possible. In areas where soil erosion by overland flow is the dominant sediment production process, river sediment yields can indeed be coupled to soil erosion rates if a spatially distributed approach is used and sediment deposition is adequately accounted for, and if the model allows for the two-dimensional nature of true landscapes (e.g.Van Rompaey et al., 2001).

Accounting for the two-dimensional nature of landscapes is to some extent possible by adapting a hillslope model so that it can account for flux divergence (on convexities) and convergence (in concavities). By doing so it is implicitly assumed that erosion rates and patterns display continuity over various landscape elements, and that gullying in hollows can be described using the same process descriptions as for rill erosion on hillslopes. There is some empirical support for this in the case of ephemeral gullying (Desmet \& Govers, 1997). Clearly, such an approach is not possible when sediment production in concavities is controlled by processes other than those described by the model, such as permanent gullying driven by headcut retreat due to surface runoff and/or groundwater seepage.

Thus, erosion models can be applied at larger scales than the hillslope provided that appropriate scaling functions are used and the results are correctly interpreted: water erosion models may well be used to predict spatial variations in soil erosion rates by sheet and rill erosion and to some extent by ephemeral gullying, but not due to other processes. Coupling simulated soil erosion rates to temporal variations in sediment yield is only possible under well-defined conditions: soil erosion should (by far) be the dominant sediment production process in the basin, and the model used needs to be able to simulate sediment transfer and deposition within the catchment. A model such as WATEM/SEDEM (Van Rompaey et al., 2001) allows this using a steady-state approach for areas where soil erosion by water is the only important sediment production process. A promising approach to develop models incorporating a wider range of processes is the use of parsimonious algorithms, as is done in the SEDNET model (Wilkinson et al., 2004).

\subsection{Misconceptions About Erosion Models}

Soil erosion modelling is an ongoing scientific activity: there is not only an increasing literature on the application of soil erosion models, but new approaches to hillslope erosion modelling continue to be developed (Wainwright et al., 2008; Heng et al., 2009; Wei et al., 2009). It is therefore 
not only important to reflect upon misapplications of models, but also on (mis)conceptions that may direct which models we will develop in the future and how we will test them. Here, we discuss a number of such misconceptions that we consider to be important. We explore to what extent commonly accepted conceptions about erosion models are indeed tenable, considering the available empirical evidence and what the possible implications of these conceptions are for future model development and applications.

\subsubsection{Misconception: 'Better' models lead to more accurate predictions (of soil erosion rates)}

The continuous development of soil erosion models has been driven, to a large extent, by the desire to improve predictions. Although not always explicitly stated, it was assumed that statistical 'average' models were inadequate to describe the complexity of soil erosion processes and did not allow sufficiently for the impact of temporal and spatial variability as well as the role of different subfactors in model input variables. While evidence of the importance of temporal variability and the role of soil and vegetation subfactors gradually accumulated in the literature from 1960 onwards, the seminal papers published by Foster and Meyer $(1972,1975)$ in conjunction with the advent of cheap computer power caused the development and testing of process-based models to progress relatively quickly from 1980 onwards.

There is no doubt that erosion models have been 'improving' over time: rather than being purely empirical and simulating average conditions only, many models are now capable of accounting for temporal variability and often contain some form of process description. Research on erosion processes is still ongoing and may lead to a further improvement of the process descriptions in the future.

One might therefore expect that the predictive capability of such newer models would exceed that of old models such as the USLE. Over recent years, several publications have appeared where the performance of statistical, average models and dynamic, process-based models has been compared. In most cases these publications focus on predictions of soil erosion rates only, i.e. the amount of soil leaving a pre-defined area subject to erosion, divided by the surface area considered and the amount of time over which measurements took place. Most often, data are collected on areas subject to net erosion over the whole surface, so the plots rarely contain zones which are characterized by net deposition.

The outcome of these comparison exercises is somewhat surprising. Overall, average annual and even annual values of soil erosion rates as measured on erosion plots are not better predicted by using a dynamic, process-based model rather than a statistical approach. As already mentioned, Tiwari et al. (2000) found that, using the data used to develop the USLE, the overall performance of the WEPP model was somewhat worse than that of the USLE. The RUSLE performed similarly to the WEPP model for average annual values, and similarly to the USLE for annual values. Other studies show similar results. Bathurst and Lukey (1998) used the SHETRAN model to simulate sediment fluxes in experimental catchments strongly affected by soil erosion in the French Alps, and found that SHETRAN performance was very mixed, with good agreement for some events while predictions were out by more than an order of magnitude for other events; overall the correlation between predicted and measured data was not significant. Using the same data and a simple, empirical model based on rainfall characteristics only as an input, Brochot and Meunier (1995) arrived at good predictions over a wide range of events $\left(\mathrm{R}^{2}=0.72-0.78\right)$. Risse et al. (1993) extensively tested the USLE and arrived at $\mathrm{R}^{2}$ values of 0.58 for annual and 0.75 for average annual values, respectively, while a similar study by Zhang et al. (1996) using the WEPP model obtained values of 0.50 and 0.65 for annual and annual average erosion rates before optimization, and values of 0.54 and 0.68 after optimization; these results are thus in line with those of Tiwari et al. (2000). Rapp et al. (2001) did not find any improvement in soil loss predictions from 206 natural runoff plots when the RUSLE was used instead of the 
USLE: model efficiencies were 0.73 for average annual and 0.58 for annual values for both models. Klik and Zartl (2001) reported that WEPP reasonably simulated soil losses for individual storms as measured on plots in Austria, but only after increasing standard inter-rill erodibility values by a factor of 9-10 and rill erodibility by a factor of $1-3$. With respect to annual values, the performance of the calibrated WEPP and uncalibrated RUSLE was similar. Stolpe (2005) found that measured erosion rates in south-central Chile were equally well predicted using the USLE and WEPP $\left(\mathrm{R}^{2}=0.86\right)$, but predictions using the RUSLE were weaker $\left(\mathrm{R}^{2}=0.50\right)$. Spaeth et al. $(2003)$ compared the performance of the USLE and RUSLE using rainfall simulation data and found that both models performed poorly: the greater flexibility of the RUSLE did not offer any advantage over the USLE. Results are broadly similar for catchment models; again, spatially distributed, dynamic models do not significantly outperform lumped models when sediment yields are compared. Im et al. (2007) compared the HSPF model, which uses detailed process descriptions but a rather rough spatial discretization, with the spatially distributed SWAT model with respect to the prediction of runoff and sediment yield for a 12,000 ha watershed in Virginia, and found that both models performed similarly with slightly better results for HSPF. Parajuli et al. (2009) found the process-based SWAT and the AnnAGNPS model to perform similarly with respect to runoff and sediment yield. SWAT did perform better, however, with respect to phosphorus export. Shen et al. (2009) reported that WEPP outperformed SWAT with respect to runoff prediction in the Zhangjiachong Watershed, but both models performed similarly with respect to sediment yield, with model efficiencies (after calibration) of 0.83 and 0.82 for WEPP and SWAT respectively.

Thus, the development of more sophisticated models does not seem to lead to better predictions. This situation is not at all unique with respect to soil erosion; similar observations have been made in hydrology, where the feasibility of deterministic hydrological modelling has been questioned for a long time (Grayson et al., 1992) and no detectable progress was made in flood prediction over two decades, despite increasing model sophistication (Welles et al., 2007).

There are at least two basic reasons for this rather uneasy situation: firstly, process-based models require much more input data, and with every input value that is required there is necessarily some uncertainty associated. As an example, WEPP uses an inter-rill erodibility factor $\left(K_{i}\right)$ that is calculated as the product of a base inter-rill erosion factor and seven subfactors (Alberts et al., 1995). Each of these eight factors is calculated using an empirical relationship to account for canopy effects, ground cover, roots, and so on. Assuming, as proposed by Alberts et al. (1995), a baseline value of $5.3 \times 10^{6}\left(\mathrm{~kg} \mathrm{~s} \mathrm{~m}^{-4}\right)$ for the base inter-rill erodibility factor and assuming, for the sake of simplicity, that each of the adjustment factors has a value of 1 and that each of the factors has an uncertainty (error standard deviation) of $10 \%$, the resulting inter-rill erodibility value will already have an uncertainty of around $28 \%$. An increase in the estimation uncertainty of the subfactors to $20 \%$ would lead to an uncertainty on the final value of around $60 \%$. Thus, as models become more sophisticated, the uncertainty associated with estimating input values inevitably increases. Even if one would, for a given point in the landscape, be able to estimate $K_{i}$ with a very high degree of accuracy, we would face a problem of uncertainty as the values for different subfactors vary significantly over space. Basically, further sophistication of a model will only result in improved predictive capabilities if the increase in prediction error resulting from an additional input data is smaller than the reduction in prediction error to a better model prediction (Van Rompaey \& Govers, 2002).

Secondly, even the most sophisticated model will not be able to capture all the variability in soil conditions that lead to variations in erosion response. This can be shown by comparing erosion measurements from replicate plots. Many erosion study sites of the USDA contained replicate plots: one might consider replicate plots as being physical models of each other (i.e. 'identical twins'). It is therefore unreasonable to expect that a simulation model can make a better 
prediction or simulation of the erosion rate observed on a single plot than that measured on the replicate plot. Indeed, the idea behind replicate plots is that they are maintained in exactly the same condition: input values used to simulate replicate plots are therefore the same. Nearing et al. (1999) clearly showed that replicates do show a high degree of variation, especially for low erosion rates. Consequently, the predictive ability of erosion models, which in principle cannot outperform the physical model (the replicate plot), is fundamentally limited. Nearing (2006) found that the upper limit that may be reached is an $R^{2}$ of 0.77 for erosion rates $>75 t / h a$. For smaller values the maximum achievable $\mathrm{R}^{2}$ is lower, as the inherent variability of erosion becomes relatively more important. It is worthwhile noting that $\mathrm{R}^{2}$ values reported in model comparison studies for average annual erosion rates are similar in magnitude (see above): this implies that the upper limit of erosion predictability appears to have been achieved, even by a statistical model such as (R)USLE.

\subsubsection{Misconception: A model is well calibrated and validated if the field/ catchment erosion rate/sediment yield is well simulated}

Most model evaluations use data collected at the outlet of the system (field, catchment) under study for calibration and validation purposes. Yet, this approach poses an important problem: it is perfectly possible that a model reproduces the right answer for the wrong reasons. Van Oost et al. (2005a) used a simple example to illustrate this: suppose that we have a catchment consisting of only two fields, $\mathrm{A}$ and $\mathrm{B}$, of equal magnitude, each making up exactly $50 \%$ of the catchment and situated on both sides of a single valley that cuts the catchment in half. It is obvious then that the catchment response will be the same when the input data for field A and field B are interchanged. Thus, a model test will not be able to show which set of input data/parameter values is associated with field A and which one is associated with field $\mathrm{B}$.
Although this example is overly simplistic, it clearly illustrates the general problem. Spatially distributed, process-based erosion models have an almost infinite number of degrees of freedom because of the many variable inputs and parameter values that need to be provided as spatial fields. Equifinality is a necessary consequence of this situation: (very) different sets of parameter values/input data lead to similar model outcomes, even over a relatively wide range of events (Beven, 2006; see also Chapter 4).

Although we often realize the above problem, we continue to compare the performance of process-based, spatial models based on 'output' at the field or catchment scale only, as these are the data that are generally available. Although the latter may be meaningful in a practical application where it needs to be decided which model is going to be applied to solve a given problem (e.g. Nasr et al., 2007), it is unlikely that such output-based model comparisons will further our scientific understanding of what is happening within the catchment. If we focus on outlet response only, we simply have too little information to optimize unequivocally a spatially distributed, processbased erosion model. Assuming that the model that is best reproducing catchment output in terms of total sediment quantities is also best at representing the processes within the catchment is, at the least, risky. Takken et al. (1999) showed that, when a spatially distributed model is optimized based on total catchment response, internal patterns of sediment production, transfer and deposition may be completely misrepresented.

We can then also expect that, when the performance of models is compared, there will be no model consistently outperforming the other models; the performance of a model in a particular situation will depend as much on its ability to accommodate variations in the catchment response through variations in the input data and the parameter values chosen for optimization, as on its 'correctness' in describing the processes occurring within the catchment. An important point here is that models having more degrees of freedom should be expected to perform better, and that this improved performance should be 
compared with the increased amount of information needed to run the model, something that is almost never accounted for in model comparison studies.

The above suggests that the problem may be (partly) solved by complementing output-based model evaluation with other information. Jetten et al. (2003) have already discussed this issue and proposed that more attention should be given to what may be called internal model validation, i.e. the degree to which the model is indeed capable of representing the spatial and temporal variations in soil (and water) redistribution within a catchment (see also Chapter 3). While data on internal sediment redistribution are usually not available on an event basis, tracer studies and soil truncation studies (Govers et al., 1996; Quine et al., 1997; Polyakov et al., 2009) can provide information on sediment redistribution patterns over the long term. Other spatial data may also be useful, such as the spatial distribution of ephemeral gullies (Nachtergaele et al., 2001) or the spatial distribution of deposition zones after an important event.

However, we should realize that there may be fundamental limits with respect to what may be achieved using spatial data; the spatial and temporal resolution of the spatial data required that we may collect will in general be at least an order of magnitude smaller than that of the input data for a spatially distributed, dynamic model, as well as of the simulated model response. Furthermore, these data will be characterized by important uncertainty. For instance, correctly estimating deposition volumes on a field is hampered by the variation in field microtopography. The uncertainty on such estimates may therefore well exceed values typical for reservoir sedimentation (i.e. 30-35\%; Verstraeten \& Poesen, 2002). Thus, spatially distributed data on sediment distribution may help to identify major shortcomings in model results, but will not allow solution of the equifinality problem entirely: the use of spatial data may help to constrain the range of 'possible' parameter values and to compare those values with physically meaningful values. By doing so we may be able to investigate to what extent a pro- posed model is indeed capable of describing the observed response. If the observed response cannot be described with reasonable parameter values, then this might be an indication that the model is structurally flawed, and is not capable of describing the processes controlling the field response.

\subsubsection{Misconception: The major advantage of process-based models is that they can be applied without a priori calibration}

The development and testing of process-based models has often been promoted through the idea that statistical models can be applied only to conditions for which they have been developed, while a process-based model may be applied to conditions different from those for which the model was developed and tested. The implicit idea behind this is that process-based models describe the basic processes leading to runoff and sediment detachment, transport and deposition. Hence, such a model should, in principle, be applicable without extensive a priori model calibration and it should be possible to use such models for ex ante evaluations.

This assumption is wrong for several reasons. One of the most important is that, while processbased models may use deterministic, well-tested process descriptions, the inputs that are necessary to run them (e.g. erodibility, soil hydrological characteristics) are usually estimated through statistical procedures. For instance, the effective hydraulic conductivity $\left(K_{\text {erange }}\left(\mathrm{mm} \mathrm{h}^{-1}\right)\right)$ for rangeland in WEPP is estimated using the following equation when the surface has $>45 \%$ rills (Alberts et al., 1995):

$$
\begin{aligned}
K_{\text {erange }}= & -14.29-3.40 \ln (\text { ROOT10 })+37.83 \text { s and } \\
& +208.86 \text { orgmat }+298.64 R R \\
& -27.39 R E S I+64.14 B A S I
\end{aligned}
$$

where ROOT10 is the root biomass in the top $0.1 \mathrm{~m}$ of the soil $\left(\mathrm{kg} \mathrm{m}^{-2}\right)$, sand is the fraction of sand in the top $0.1 \mathrm{~m}$ of the soil, $R R$ is the random roughness $(\mathrm{m}), R E S I$ is the fraction of litter surface 
cover in inter-rill areas, and BASI is the production of the fraction of basal surface cover in interrill areas and total basal surface cover.

These procedures have been developed using a calibration and validation dataset and are therefore subject to the same limitations as statistical erosion models. As process-based models are very sensitive to input data and/or parameter values, one should therefore only apply them for these conditions where the statistical input value estimation procedures were properly validated. If input values need to be estimated for conditions that are different from those for which input value estimation procedures were developed, erroneous results may be expected.

Even if the model is used in conditions similar to those for which input value estimation procedures were developed, there will be considerable uncertainty associated with the parameter values obtained from the estimation procedures, and the resulting uncertainty on the final model result may well be bigger than that for a statistical model. Quinton (1997) convincingly showed that, in a simple application of the EUROSEM model, the impact of input value uncertainty on the final model result was such that a meaningful model evaluation became impossible. The range of possible output simulations was such that the measured outcome always fell within the lower and upper possible limits, and it was therefore impossible to evaluate the model properly; given the uncertainty in parameter estimates, it was possible that the model properly simulated the measured events but poor simulations were in fact equally probable (see also Chapter 5).

The uncertainties in input values are not only due to the statistical nature of parameter estimation techniques. There is also a considerable error associated with the actual measurement or estimation of the data necessary for input value estimation. We often have to rely on very few and very small samples or a limited number of point measurements to estimate soil bulk density, moisture content, roughness and vegetation cover. The loss of prediction accuracy due to uncertainty in both input data and in input value estimation may outweigh possible gains in accuracy due to a better process description, thereby leading to a decrease in model performance with increasing model complexity (Van Rompaey \& Govers, 2002).

This does not imply that we should not apply process-based, spatially distributed models to ungauged fields and catchments, but we should not expect their predictions to be quantitatively superior to those obtained with simpler, statistical or black-box model structures. A priori calibration/evaluation is as necessary for spatially distributed process-based models as for statistical models; neglecting this prerequisite may lead to erroneous evaluations which may have important practical implications (Nyssen et al., 2006; see also Chapter 3).

\subsubsection{Misconception: Erosion models now simulate what is needed by science and society: further model development and testing is therefore unnecessary}

Given the fact that a wide range of soil erosion models exists, one might indeed expect there to be an erosion model for every potential application either from a scientific or a societal viewpoint. We would argue that this is not (yet) the case. Below we focus on two 'missing links' which are relatively poorly represented in most erosion models: the modelling of sediment size-selectivity and the modelling of erosion-soil interactions.

Current needs with respect to soil erosion modelling are no longer limited to the simulation of the total amount of soil redistribution within a landscape. Recent literature devotes a considerable amount of attention to the movement of sediment-associated nutrients, pollutants and organic matter. As the latter are mainly bound to the fine fraction, understanding how the fine soil fraction is mobilized and transported through the landscape becomes crucial. Many current models have the ability to deal with different size fractions and are capable of simulating the redistribution of sediment-associated soil constituents. Various approaches have been proposed, ranging from the use of simple enrichment ratios in association with statistical models (Foster et al., 2003), to process-based approaches describing the 
dynamics of the various size fractions in detail (Hairsine \& Rose, 1992). However, compared with the efforts that have historically been made to collect data for model testing focusing on total soil erosion, there are relatively few datasets available that allow the testing of models describing sizeselectivity. One of the reasons is that traditional field plots almost exclusively focused on areas where net erosion occurs; while size-selectivity may occur when sediment is detached, depositional processes are potentially even more selective than detachment processes (Beuselinck et al., 1999). Understanding deposition is also important because deposition may lead to temporary storage and remobilization of sediment (Krueger et al., 2009). As most field experiments on erosion were (and probably still are) located on areas without net deposition, the amount of data that is available to test various approaches to selective deposition modelling is relatively limited, and only limited model testing has been carried out (e.g. Beuselinck et al., 1999). Sometimes the potential of a model to predict the movement of fine sediment and associated soil constituents is evaluated using data collected at the catchment outlet (Nasr et al., 2007). It is evident that this approach holds potential, but that the resulting model calibration may be very specific for the conditions tested due to the issues we discussed earlier (see Chapter 13 as an example).

One of the major difficulties in deposition modelling is the prediction of the actual sediment size distribution of the transported sediment. It has been known for a long time that eroded sediment is often transported in the form of (micro-) aggregates, a fact that has profound implications. The fact that colluvial soils often have a grain-size composition similar to the eroding soils from which they were derived can only be explained by the fact that most of the colluvium was indeed deposited in the form of (micro-)aggregates (Beuselinck et al., 2000). Understanding the dynamics of aggregation during an erosion event is key to understanding size selectivity and enrichment. Recently developed measurement techniques offer some perspective here: it is now for instance possible to measure the size distribution of transported sediment on the fly using laser diffractometry
(Williams et al., 2007). An additional complication is that the (micro-)topography of depositional surfaces and therefore the runoff hydraulics may change very rapidly once deposition occurs. Often, one can observe depositional surfaces being reincised by consecutive events or even in the last phase of the event causing the deposition in the first place; the mobilization of previously deposited material is possible when the sediment load of the runoff water reaching the depositional zone is well below sediment-transporting capacity (Plate 3). Models accounting for these interactions between sediment deposition, runoff hydraulics and sediment load are at present non-existent.

At this point one might wonder why we should develop our models further in order to include these complicated processes. It is indeed unlikely that further refinement of the description of depositional processes in process-based, dynamic models will greatly improve our predictive capabilities with respect to erosion rates and/or gross sediment yield. Yet, the objective of models is not only to predict the impact of future events or to simulate past data correctly; models are also scientific tools to enhance our understanding of how landscapes function. Evaluating models for sediment deposition and particle size-selectivity using appropriate field and laboratory data will allow us to judge to what extent we really understand the processes we are interested in, which is a valid scientific objective on its own. Also, better understanding does not necessarily have to lead to more complex process models, which are often more difficult to calibrate and/or validate. In some cases better understanding may also help to decide where and how a model can be simplified without losing predictive power, thereby allowing for more efficient model calibration. Van Oost et al. (2004) were able to show that sediment re-entrainment was not important to describe sediment deposition on, and export from, eroding fields in Central Belgium: hence, a simpler model structure not including re-entrainment could also be used successfully. However, the effect of such simplifications may strongly depend on local conditions and they therefore need to be applied with care. A better understanding of the 
factors controlling deposition rates and sediment enrichment has important practical applications as well, since it will, for instance, help us to decide which measures in a catchment will be most effective in reducing not only total sediment yield, but also the movement of different sediment size classes, even if we cannot always make a correct quantitative prediction.

The focus of erosion modelling on simulating correctly the total quantity of soil movement has also led to neglect of what is actually eroding - the soil. Soils are an important part of ecosystems, providing services to human society. The potential of soils to provide these services depends on their quality, which is undoubtedly affected by erosion. The most important service provided by agricultural soils is the production of crops, and one would therefore expect that over the years a large observational database would have been established on the relationship between erosion and crop productivity. Surprisingly, this is not the case: although some data have been collected, many of them were obtained using rapid desurfacing, a method that is not capable of simulating the gradual removal of soil by erosion and leads to strong overestimation of erosion effects on agricultural productivity (Bakker et al., 2004). Other data were collected under more realistic conditions, but do not account for the confounding effect of landscape position: eroded soils are located in specific landscape positions (steep slopes, convexities) that may be inherently less productive than concavities and footslopes (Stone et al., 1985; Bakker et al., 2004).

This important hiatus can be filled by setting up specific activities whereby the erosionproductivity link is studied using an integrated approach under various agro-ecological conditions. The latter is a necessity, as the effect of erosion on crop productivity is known to depend on soil properties (Dercon et al., 2006), but will also depend on the agricultural system. Under highinput agriculture the negative effects of erosion on nutrient supply are compensated for by fertilization, so that the effect of erosion on crop yield is ultimately controlled by the effect of erosion on the ability of the soil to store water and make it available for plant growth (Bakker et al., 2005).
However, in low-input agriculture, the effects of nutrient losses may indeed have strong effects on crop productivity (Dercon et al., 2006).

Erosion-soil interactions are not limited to soil productivity. Soil properties can dramatically change due to erosion effects: for instance, if rock fragments are present, erosion rates may be dramatically reduced on a decadal time-scale due to the concentration of protective rock fragments at the surface. As the reduction of erosion rates will be greatest in locations where initial erosion rates are highest, this will also lead to significant changes in erosion patterns in the landscape (Govers et al., 2006). Erosion will also lead to the redistribution of soil organic matter which has profound implications for the carbon exchange between the soil and the atmosphere (Van Oost et al., 2005b). Such long-term interactions need to be explicitly accounted for in models designed to simulate erosion over longer time spans.

Further model development efforts will not result in the ultimate universal soil erosion model. Depending on the research objectives, different approaches are necessary. Modelling within-field carbon or nutrient redistribution by erosion over long time-scales does not require a dynamic model, but can be studied using a steadystate approach (Van Oost et al., 2003). On the other hand, studying sediment delivery to watercourses where event size may be crucial requires the use of a high temporal resolution model (Van Oost et al., 2004; Fiener et al., 2008). Thus, several types of models will also co-exist in the future in order to address different issues.

\subsection{Conclusions}

Misapplications and misconceptions of erosion models can be discussed from different perspectives. Here we took a rather pragmatic viewpoint of this issue and discussed how misapplications of models may be related to applications of models at inappropriate spatial and temporal scales and/ or to a spatial domain where processes other than those represented in the model contribute significantly to sediment redistribution. Upscaling a 
model to large areas requires not only that all processes that are relevant over a larger spatial scale are included in the model description. It is also necessary to use appropriate scaling functions; understanding how soil erosion rates depend on slope length or unit contributing area over the domain to be modelled is critical in this respect.

Misconceptions about soil erosion models do not always lead to misapplications. Even if this is not the case, however, misconceptions may have important consequences as they may (mis)guide scientific efforts. A particularly important misconception is that increasing model quality will be expressed in improved predictions of absolute erosion rates at increasingly smaller temporal scales. This will not happen as there is a fundamental upper limit to prediction accuracy, and it appears that even the performance of older, statistically based models, such as the (R)USLE, is close to this limit.

The latter does not imply, however, that sophisticated, spatially distributed, process-based models are useless. Rather, they are tools that allow us to improve our understanding of how erosion and deposition processes work at different scales, allowing us to move away from the plot to real landscapes. The development of such models requires a continuous confrontation of field and laboratory data with model predictions. Temporally and spatially detailed data are necessary to test thoroughly the last generation of erosion models. Confrontation of model performance with field or laboratory observations should be designed in such a way that it allows assessment of which of any competing model concepts is 'better' in terms of describing the data and why this is the case. As the necessary field data or laboratory data to do this are often not available, there is a risk that efforts are uniquely directed towards the improvement of model performance through parameter optimization. By doing so, we miss the opportunity that models give us to evaluate to what extent they are really capturing the complex interplay between hydrology, erosion and (size-selective) deposition that takes place in real landscapes. Erosion models will also need further development in order to make them suit- able tools to answer scientifically and societally relevant questions that even the most sophisticated, present-day models cannot fully address, such as erosion-soil interactions at different scales and the size-selective transfer of sediment and associated nutrients, pollutants and organic matter through a landscape.

\section{References}

Alberts, E.E., Nearing, M.A., Weltz, M.A., et al. (1995) Soil component. In Flanagan, D.C. \& Nearing, M.A. (eds), USDA - Water Erosion Prediction Project: Hillslope profile and watershed model documentation. NSERL Report No. 10. USDA-ARS National Soil Erosion Laboratory, West Lafayette, Indiana, pp. 7.1-7.46.

Baffaut, C., Nearing, M.A. \& Govers, G. (1998) Statistical distributions of soil loss from runoff plots and WEPP model simulations. Soil Science Society of America Journal 62: 756-63.

Bakker, M.M., Govers, G. \& Rounsevell, M.D.A. (2004) The crop productivity-erosion relationship: an analysis based on experimental work. Catena 57: 55-76.

Bakker, M.M., Govers, G., Ewert, F., et al. (2005) Variability in regional wheat yields as a function of climate, soil and economic variables: assessing the risk of confounding. Agriculture Ecosystems 4 Environment 110: 195-209.

Bathurst, J.C. \& Lukey, B. (1998) Modelling badlands erosion with SHETRAN at Draix, southeast France. In Summer, W., Klaghofer, E. \& Zhang, W. (eds), Modelling Soil Erosion, Sediment Transport and Closely Related Hydrological Processes. IAHS Publication 249, pp. 129-36.

Belyaev, V.R., Wallbrink, P.J., Golosov, V.N., et al. (2005) A comparison of methods for evaluating soil redistribution in the severely eroded Stavropol region, southern European Russia. Geomorphology 65: 173-93.

Beuselinck, L., Govers, G., Steegen, A., et al. (1999) Evaluation of the simple settling theory for predicting sediment deposition by overland flow. Earth Surface Processes and Landforms 24: 993-1007.

Beuselinck, L., Steegen, A., Govers, G., et al. (2000) Characteristics of sediment deposits formed by intense rainfall events in small catchments in the Belgian Loam Belt. Geomorphology 32: 69-82.

Beven, K. (2006) A manifesto for the equifinality thesis. Journal of Hydrology 320: 18-36. 
Boardman, J. (2006) Soil erosion science: reflections on the limitations of current approaches. Catena 68: 73-86.

Bras, R.L., Tucker, G.E. \& Teles, V. (2003) Six myths about mathematical modelling in geomorphology. Geophysical Monograph 135: 63-79.

Brochot, S. \& Meunier, M. (1995) Erosion de badlands dans les Alpes du sud: synthése. In Meunier, M. (ed.), Compte-rendu de recherches n ${ }^{\circ}$ : BVRE de Draix. Equipements pour l'eau et l'environnement $n^{\circ} 21$. Cemagref Editions, pp. 141-74.

Busacca, A.J., Cook, C.A. \& Mulla, D.J. (1993) Comparing landscape-scale estimation of soil-erosion in the Palouse using Cs-137 and RUSLE. Journal of Soil and Water Conservation 48: 361-7.

Cammeraat, L.H. (2002) A review of two strongly contrasting geomorphological systems within the context of scale. Earth Surface Processes and Landforms 27: 1201-22.

De Roo, A.P.J. \& Jetten, V.G. (1999) Calibrating and validating the LISEM model for two data sets from The Netherlands and South Africa. Catena 37: 477-93.

Dercon, G., Deckers, J., Poesen, J., et al. (2006) Spatial variability in crop response under contour hedgerow systems in the Andes region of Ecuador. Soil e) Tillage Research 86: 15-26.

Desmet, P.J.J. \& Govers, G. (1997) Two-dimensional modelling of the within-field variation in rill and gully geometry and location related to topography. Catena 29: 283-306.

Dunne, T., Zhang, W.H. \& Aubry, B.F. (1991) Effects of rainfall, vegetation, and microtopography on infiltration and runoff. Water Resources Research 27: 2271-85

Favis-Mortlock, D.T. Boardman, J. \& MacMillan, V.J. (2001) The limits of erosion modeling: why we should proceed with care. In Harmon, R.S. \& Doe, W.W. III (eds), Landscape Erosion and Evolution Modeling. Kluwer Academic, New York: 477-516.

Fiener, P., Govers, G. \& Van Oost, K. (2008) Evaluation of a dynamic multi-class sediment transport model in a catchment under soil-conservation agriculture. Earth Surface Processes and Landforms 33: 1639-60.

Flanagan, D.C. \& Nearing, M.A. (eds) (1995) USDA Water Erosion Prediction Project: hillslope profile and watershed model documentation. NSERL Report 10, USDA-ARS National Soil Erosion Laboratory, West Lafayette, Indiana.

Foster, G.R. \& Meyer, L.D. (1972) A closed-form equation for upland areas. In Shen, H. (ed.), Sedimentation. Symposium to Honor Prof. H.A. Einstein, Fort Collins, pp. 12.1-12.17.
Foster, G.R. \& Meyer, L.D. (1975) Mathematical simulation of upland erosion by fundamental erosion mechanics. In Present and prospective technology for predicting sediment yields and sources. Agricultural Research Service Report ARS-S-40, pp. 190-207.

Foster, G.R., Toy, T.E. \& Renard, K.G. (2003) Comparison of the USLE, RUSLE 1.06c and RUSLE2 for application to highly disturbed lands. In Renard, K.G., McElroy, S., Gburek, W., et al. (eds), Proceedings, 1st Interagency Conference on Research in the watersheds. Benson, AZ, pp. 154-60.

Govers, G., Vandaele, K., Desmet, P., et al. (1994) The role of tillage in soil redistribution on hillslopes. European Journal of Soil Science 45: 469-78.

Govers, G., Quine, T.A., Desmet, P.J.J. \& Walling, D.E. (1996) The relative contribution of soil tillage and overland flow erosion to soil redistribution on agricultural land. Earth Surface Processes and Landforms 21: 929-46.

Govers, G., Van Oost, K. \& Poesen, J. (2006) Responses of a semi-arid landscape to human disturbance: a simulation study of the interaction between rock fragment cover, soil erosion and land use change. Geoderma 133: 19-31.

Govers, G., Gimenez, R. \& Van Oost, K. (2007) Rill erosion: exploring the relationship between experiments, modelling and field observations. Earth-Science Reviews 84: 87-102.

Grayson, R.B., Moore, I.D. \& McMahon, T.A. (1992) Physically based hydrologic modeling. 2. Is the concept realistic? Water Resources Research 28: 2659-66.

Hairsine, P.B. \& Rose, C.W. (1992) Modeling water erosion due to overland-flow using physical principles. 2. Rill flow. Water Resources Research 28: 245-50.

Heng, B.C.P., Sander, G.C. \& Scott, C.F. (2009) Modeling overland flow and soil erosion on nonuniform hillslopes: A finite volume scheme. Water Resources Research 45: W05423.

Im, S.J., Brannan, K.M., Mostaghimi, S. \& Kim, S.M. (2007) Comparison of HSPF and SWAT models performance for runoff and sediment yield prediction. Journal of Environmental Science and Health Part A:Toxic/Hazardous Substances ↔ Environmental Engineering 42: 1561-70.

Ito, A. (2007) Simulated impacts of climate and landcover change on soil erosion and implication for the carbon cycle, 1901 to 2100. Geophysical Research Letters 34: [Note(s): L09403.1-L09403.5].

Jetten, V., de Roo, A. \& Favis-Mortlock, D. (1999) Evaluation of field-scale and catchment-scale soil erosion models. Catena 37: 521-41. 
Jetten, V., Govers, G. \& Hessel, R. (2003) Erosion models: quality of spatial predictions. Hydrological Processes 17: 887-900.

Jetten, V. \& Favis-Mortlock, D. (2006) Modelling soil erosion in Europe. In Boardman, J. \& Poesen, J. (eds), Soil Erosion in Europe. John Wiley \& Sons, Chichester: 695-716.

Kirkby, M.J., Irvine, B.J., Jones, R.J.A., et al. (2008) The PESERA coarse scale erosion model for Europe. I. Model rationale and implementation. European Journal of Soil Science 59: 1293-1306.

Klik, A. \& Zartl, A.S. (2001) Comparison of soil erosion simulations using WEPP and RUSLE with field measurements. In Ascough, J.C. II \& Flanagan, D.C. (eds), Soil Erosion Research for the 21st Century. American Society of Agricultural Engineers, St. Joseph, MI: 350-53.

Krueger, T., Quinton, J.N., Freer, J., et al. (2009) Uncertainties in data and models to describe event dynamics of agricultural sediment and phosphorus transfer. Journal of Environmental Quality 38 : $1137-48$.

Lal, R. (2003) Soil erosion and the global carbon budget. Environment International 29: 437-50.

Loch, R.J. (1996) Using rill/interrill comparisons to infer likely responses of erosion to slope length: implications for land management. Australian Journal of Soil Research 34: 489-502.

Mutchler, C.K. \& Carter, C.E. (1983) Soil erodibility variation during the year. Transactions of the American Society of Agricultural Engineers 26: 1102-4.

Nachtergaele, J., Poesen, J., Steegen, A., et al. (2001) The value of a physically based model versus an empirical approach in the prediction of ephemeral gully erosion for loess-derived soils. Geomorphology 40: 237-52.

Nasr, A., Bruen, M., Jordan, P., et al. (2007) A comparison of SWAT, HSPF and SHETRAN/GOPC for modelling phosphorus export from three catchments in Ireland. Water Research 41: 1065-73.

Nearing, M.A. (2006) Can soil erosion be predicted? In Owens, P.N. \& Collins, A.J. (eds), Soil Erosion and Sediment Redistribution in River Catchments. CAB International, Wallingford: 145-52.

Nearing, M.A., Foster, G.R., Lane, L.J. \& Finkner, S.C. (1989) A process-based soil-erosion model for USDAWater Erosion Prediction Project Technology. Transactions of the American Society of Agricultural Engineers 32: 1587-93.

Nearing, M.A., Govers, G. \& Norton, L.D. (1999) Variability in soil erosion data from replicated plots. Soil Science Society of America Journal 63: 1829-35.
Nyssen, J., Haregeweyn, N., Descheemaeker, K., et al. (2006) Comment on "Modelling the effect of soil and water conservation practices in Tigray, Ethiopia" [Agric. Ecosyst. Environ. 105 (2005) 29-40]. Agriculture Ecosystems and Environment 114: 407-11.

Parajuli, P.B., Nelson, N.O., Frees, L.D. \& Mankin, K.R. (2009) Comparison of AnnAGNPS and SWAT model simulation results in USDA-CEAP agricultural watersheds in south-central Kansas. Hydrological Processes 23: 748-63.

Parsons, A.J., Brazier, R.E., Wainwright, J. \& Powell, D.M. (2006) Scale relationships in hillslope runoff and erosion. Earth Surface Processes and Landforms 31: 1384-93.

Polyakov, V.O., Kimoto, A., Nearing, M.A. \& Nichols, M.H. (2009) Tracing sediment movement on a semiarid watershed using rare earth elements. Soil Science Society of America Journal 73: 1559-65.

Quine, T.A., Govers, G., Walling, D.E., et al. (1997) Erosion processes and landform evolution on agricultural land - new perspectives from caesium-137 measurements and topographic-based erosion modelling. Earth Surface Processes and Landforms 22: 799-816.

Quinton, J.N. (1997) Reducing predictive uncertainty in model simulations: a comparison of two methods using the European Soil Erosion Model (EUROSEM). Catena 30: 101-17.

Rapp, J.F., Lopes, V.L. \& Renard, K.G. (2001) Comparing soil erosion estimates from the USLE and RUSLE on natural runoff plots. In Ascough, J.C. \& Flanagan, D.C. (eds), Soil Erosion Research for the 21st Century. American Society of Agricultural Engineers, St Joseph, MI: 24-7.

Renard, K.G., Foster, G.R., Weesies, G.A., et al. (1997) Predicting soil erosion by water: a guide to conservation planning with the Revised Universal Soil Loss Equation (RUSLE). Agricultural Handbook 703, US Department of Agriculture.

Risse, L.M., Nearing, M.A., Nicks, A.D. \& Laflen, J.M. (1993) Error assessment in the Universal Soil Loss Equation. Soil Science Society of America Journal 57: 825-33.

Shen, Z.Y., Gong, Y.W., Li, Y.H., et al. (2009) A comparison of WEPP and SWAT for modeling soil erosion of the Zhangiiachong Watershed in the Three Gorges Reservoir Area. Agricultural Water Management 96: 1435-42.

Spaeth, K.E., Pierson, F.B., Weltz, M.A. \& Blackburn, W.H. (2003) Evaluation of USLE and RUSLE estimated soil loss on rangeland. Journal of Range Management 56: 234-46. 
Stolpe, N.B. (2005) A comparison of the RUSLE, EPIC and WEPP erosion models as calibrated to climate and soil of south-central Chile. Acta Agriculturae Scandinavica Section B: Soil and Plant Science 55: 2-8.

Stone, J.R., Gilliam, J.W., Cassel, D.K., et al. (1985) Effect of erosion and landscape position on the productivity of Piedmont soils. Soil Science Society of America Journal 49: 987-91.

Syvitski, J.P.M., Vorosmarty, C.J., Kettner, A.J. \& Green, P. (2005) Impact of humans on the flux of terrestrial sediment to the global coastal ocean. Science 308: 376-80.

Takken, I., Beuselinck, L., Nachtergaele, J., et al. (1999) Spatial evaluation of a physically-based distributed erosion model (LISEM). Catena 37: 431-47.

Tiwari, A.K., Risse, L.M. \& Nearing, M.A. (2000) Evaluation of WEPP and its comparison with USLE and RUSLE. Transactions of the American Society of Agricultural Engineers 43: 1129-35.

Trimble, S.W. (1999) Decreased rates of alluvial sediment storage in the Coon Creek Basin, Wisconsin, 1975-93. Science 285: 1244-6.

Van Oost, K., van Muysen, W., Govers, G., et al. (2003) Simulation of the redistribution of soil by tillage on complex topographies. European Journal of Soil Science 54: 63-76.

Van Oost, K., Beuselinck, L., Hairsine, P.B. \& Govers, G. (2004) Spatial evaluation of a multi-class sediment transport and deposition model. Earth Surface Processes and Landforms 29: 1027-44.

Van Oost, K., Govers, G., Cerdan, O., et al. (2005a) Spatially distributed data for erosion model calibration and validation: The Ganspoel and Kinderveld datasets. Catena 61: 105-21.

Van Oost, K., Govers, G., Quine, T.A., et al. (2005b) Landscape-scale modeling of carbon cycling under the impact of soil redistribution: the role of tillage erosion. Global Biogeochemical Cycles 19: GB4014. DOI: 10.1029/2005GB002471

Van Oost, K.. Quine, T.A., Govers, G., et al. (2007) The impact of agricultural soil erosion on the global carbon cycle. Science 318: 626-9.

Van Rompaey, A.J.J. \& Govers, G. (2002) Data quality and model complexity for regional scale soil erosion prediction. International Journal of Geographical Information Science 16: 663-80.

Van Rompaey, A.J.J., Verstraeten, G., Van Oost, K., et al. (2001) Modelling mean annual sediment yield using a distributed approach. Earth Surface Processes and Landforms 26: 1221-36.
Verstraeten, G. \& Poesen, J. (2002) Using sediment deposits in small ponds to quantify sediment yield from small catchments: possibilities and limitations. Earth Surface Processes and Landforms 27: 1425-39.

Wainwright, J., Parsons, A.J., Müller, E.N., et al. (2008) A transport-distance approach to scaling erosion rates: I. Background and model development. Earth Surface Processes and Landforms 33: 813-26.

Wei, H., Nearing, M.A., Stone, J.J., et al. (2009) A new splash and sheet erosion equation for rangelands. Soil Science Society of America Journal 73: 1386-92.

Welles, E., Sorooshian, S., Carter, G. \& Olsen, B. (2007) Hydrologic verification - a call for action and collaboration. Bulletin of the American Meteorological Society 88: 503-11.

Wilkinson, B.H. \& McElroy, B.J. (2007) The impact of humans on continental erosion and sedimentation. Geological Society of America Bulletin 119: 140-56.

Wilkinson, S., Henderson, A. \& Chen, Y. (2004) SedNet User Guide, Client Report. CSIRO Land and Water, Canberra.

Williams, N.D., Walling, D.E. \& Leeks, G.J.L. (2007) High temporal resolution in situ measurement of the effective particle size characteristics of fluvial suspended sediment. Water Research 41: 1081-93.

Wischmeier, W.H. (1976) Use and misuse of Universal Soil Loss Equation. Journal of Soil and Water Conservation 31: 5-9.

Wischmeier, W.H. \& Smith, D.D. (1965) Predicting rainfall erosion losses from cropland east of the Rocky Mountains. Agricultural Handbook 282, US Department of Agriculture.

Wischmeier, W.H. \& Smith, D.D. (1978) Predicting rainfall erosion losses - a guide to conservation planning. Agricultural Handbook 537, US Department of Agriculture.

Yang, D.W., Kanae, S., Oki, T., et al. (2003) Global potential soil erosion with reference to land use and climate changes. Hydrological Processes 17: 2913-28.

Zhang, X.C., Nearing, M.A., Risse, L.M. \& McGregor, K.C. (1996) Evaluation of WEPP runoff and soil loss predictions using natural runoff plot data. Transactions of the American Society of Agricultural Engineers 39: 855-63.

Zingg, A.W. (1940) Degree and length of land slope as it affects soil loss in runoff. Agricultural Engineering 21: 59-64. 